\title{
Music performance anxiety: perceived causes, coping strategies and clinical profiles of Brazilian musicians
}

\author{
Ansiedade de performance musical: causas percebidas, estratégias de \\ enfrentamento e perfil clínico de músicos brasileiros
}

Ana Beatriz Burin, ${ }^{1}$ Ana Elisa Medeiros Barbar, ${ }^{1}$ Ivan Sérgio Nirenberg, ${ }^{2}$ Flávia de Lima Osório ${ }^{1,3}$ (D)

\begin{abstract}
Introduction: Music performance anxiety (MPA) is characterized by long-lasting, high intensity apprehension associated with performing music in public. At extreme levels, MPA can impair the career and quality of life. Our goal is to describe the clinical profile, perceived causes and coping strategies associated with MPA.

Methods: In this cross-sectional study, several self-assessment instruments were administered to a sample of 214 Brazilian musicians ( $68 \%$ male, $53.3 \%$ classical $/ 46.7 \%$ popular musicians). Data were analyzed using descriptive and parametric statistics, based on the variables of musical training and level of MPA.

Results: Percentages of indicators of pathology were high ( $40 \%$ high MPA levels, $37 \%$ social anxiety, $12.5 \%$ depression, $13.5 \%$ alcohol abuse), and musicians with high MPA levels were the most affected. A wide variety of situations were associated with MPA, especially those related to the individual (pressure from self/ concern about audience). Emotion-focused coping and internal resources were prominent among the resources used for coping with MPA (breathing, increased practice, familiarization with performance venue), although they were not always effective. It was relatively uncommon for musicians to seek specialized resources and treatments.

Conclusions: The results demonstrate the vulnerability of the targeted professional groups and the need for preventive strategies and behavioral, environmental, educational, and pharmacological interventions to change this scenario.

Keywords: Anxiety, music performance, coping strategies, musicians, psychopathology.
\end{abstract}

\section{Resumo}

Introdução: Ansiedade de performance musical (APM) é definida como uma condição de apreensão duradoura e intensa, associada ao desempenho musical em público. Em níveis extremos é prejudicial à carreira e qualidade de vida do músico. Objetiva-se descrever o perfil clínico, as causas percebidas e estratégias de enfrentamento da APM.

Métodos: Neste estudo transversal, vários instrumentos de autoavaliação foram administrados a 214 músicos brasileiros ( $68 \%$ do sexo masculino, $53,3 \%$ clássicos/ $46,7 \%$ populares). Os dados foram analisados por estatística descritiva e paramétrica, com base nas variáveis formação musical e nível de APM.

Resultados: Encontrou-se um percentual elevado de indicadores de psicopatologia (40\% altos níveis de APM, 37\% ansiedade social, $12,5 \%$ depressão, 13,5\% abuso de álcool), sendo os músicos com altos níveis de APM aqueles com maior comprometimento. Uma ampla variedade de situações foi associada à APM, com destaque para aquelas relacionadas ao próprio indivíduo (pressão de si próprio/preocupação com a plateia). Entre os recursos utilizados para enfrentamento da APM destacaram-se aqueles focados na regulação emocional e no uso de recursos internos dos músicos (respiração, aumento do treino, familiarização com a prática no local da apresentação), embora nem sempre tenham sido eficazes. Mostrou-se pouco comum a busca por recursos e tratamentos especializados.

Conclusões: Evidencia-se a condição de vulnerabilidade desse grupo profissional e a necessidade de estratégias preventivas e intervenções comportamentais, ambientais, educativas e farmacológicas que permitam mudanças neste cenário.

Descritores: Ansiedade, performance musical, estratégias de enfrentamento, músicos, psicopatologia.

\footnotetext{
${ }^{1}$ Departamento de Neurociências e Ciências do Comportamento, Faculdade de Medicina de Ribeirão Preto da Universidade de São Paulo (FMRP-USP), Ribeirão Preto, SP, Brazil. ${ }^{2}$ Escola de Música, Universidade Federal do Rio de Janeiro (UFRJ), Rio de Janeiro, RJ, Brazil. ${ }^{3}$ Instituto Nacional de Ciência e Tecnologia Translacional Medicina (INCT-TM), Brasília, DF, Brazil.

This article was based on the first author's master's dissertation presented at Programa de Pós-Graduação em Saúde Mental, Faculdade de Medicina de Ribeirão Preto da Universidade de São Paulo (FMRP-USP), Ribeirão Preto, SP, Brazil.

Partial findings were presented as poster in XXXIV Congresso Brasileiro de Psiquiatria, held in 2016, in São Paulo, SP, Brazil.

Submitted Aug 21 2018, accepted for publication Mar 062019.

Suggested citation: Burin AB, Barbar AE, Nirenberg IS, Osório FL. Music performance anxiety: perceived causes, coping strategies and clinical profiles of Brazilian musicians. Trends Psychiatry Psychother. 2019;41(4):348-357. http://dx.doi.org/10.1590/2237-6089-2018-0104
} 


\section{Introduction}

Music performance anxiety (MPA) is a condition characterized bylong-lasting, high intensityapprehension associated with performing music in public. It varies from a state considered common among musicians to extreme levels that are considered pathological. ${ }^{1,2}$ Empirical studies indicate that MPA can be understood and classified as a subtype of social anxiety disorder (i.e., MPA shares the same diagnostic criteria as social anxiety disorder, but the fear is restricted to performing in public, which is why the specifier "performance only" is used to classify it). ${ }^{1,3}$ As such, it could be treated with relative efficacy. ${ }^{4}$ MPA has negative implications for musicians' careers and quality of life, with extreme situations leading to an early exit from the profession. ${ }^{2}$

Although the prevalence of MPA has not been precisely established, a literature review $^{5}$ reported significant rates ranging from $15 \%$ to $25 \%$ worldwide. In Brazil, the prevalence in a sample of professional and amateur musicians was $24 \% .^{2}$

These substantial rates notwithstanding, MPA has rarely been investigated, recognized and diagnosed. Many musicians and healthcare providers believe MPA to be inherent to the profession. Consequently, the possibilities for management, treatment and prevention of MPA are restricted, contributing to increased difficulties and suffering for affected individuals. ${ }^{4}$ Furthermore, as is widely known, a significant number of musicians selfadminister medications, especially when anticipating a performance, or employ ineffective coping mechanisms, which are often derived from personal strategies. ${ }^{6-8}$

Such scenarios are a cause for concern and demand attention and action within the public health and musical education fields to develop preventive strategies and implement behavioral, environmental, educational and even pharmacological strategies. The purpose of this study was to describe the clinical profile, perceived causes and strategies for coping with MPA from the perspective of a sample of Brazilian musicians, as a function of their MPA levels and musical training. ${ }^{4}$

\section{Methods}

The study was approved by the local ethics committee (Process no. 2855/2015).

A convenience sample comprising 214 Brazilian professional musicians was assessed. Participants who had completed undergraduate courses in music and had professional ties to orchestras were categorized as classical musicians. Popular musicians were self-defined as musicians and regularly performed for audiences in various settings (such as bars, religious ceremonies and parties) but did not have academic training in music.

Recruitment was conducted in various states of Brazil and involved the country's main orchestras and university music schools. The inclusion criteria were as follows: musicians of either sex, over the age of 18 , who perform for large audiences at least once a month, and agreed to voluntary participation in the study, as indicated by signature of an informed consent form. The only exclusion criterion was failure to fill out all of the self-assessment instruments.

The instruments used for data collection are described below.

\section{Kenny Music Performance Anxiety Inventory, revised (KMPAI)}

This is a 40 -item inventory developed by Kenny ${ }^{9}$ to assess anxiety vis-à-vis music performances. It is a revised and expanded version of an earlier 24-item inventory. ${ }^{10} \mathrm{~A}$ version translated, adapted and validated for Brazilian Portuguese ${ }^{11}$ was used. The internal consistency (Cronbach's alpha) of this version of the instrument is 0.96 . The cutoff point for defining high levels of MPA is $108 .{ }^{10}$

\section{Anxiety Sensitivity Index}

This is a 16 -item instrument ${ }^{12}$ for identifying the level of anxiety individuals experience in specific situations. It is subdivided into physical (physiological aspects), mental (cognitive aspects) and social (social aspects) subscales. A version translated into Brazilian Portuguese was used. ${ }^{13}$ The internal consistency of this instrument in that study was 0.88 (Cronbach's alpha).

\section{Causes of Music Performance Anxiety Checklist}

This instrument ${ }^{14}$ comprises a 22-item checklist of commonly perceived causes of MPA. Respondents are first requested to choose between yes and no options for each item on a list of factors that might contribute to MPA. They are then requested to classify the items they marked as yes in order of relevance. Number (1) is attributed to the most significant factor/cause, and the remainder of factors/causes are numbered consecutively. This version was translated into Brazilian Portuguese. ${ }^{13}$

\section{Self-management of Music Performance Anxiety Rating Scale}

This is an 18-item self-assessment scale that seeks to identify strategies used by musicians to self-manage MPA. ${ }^{14}$ Respondents are first requested to indicate the strategies they most commonly use, attributing a score of (1) to the most frequently used and numbering the 
remaining strategies consecutively. Next, respondents are required to indicate the effectiveness of each strategy on a 4-point Likert scale ( $0=$ not effective at all, 3 = very effective). A version translated into Brazilian Portuguese was used. ${ }^{13}$

\section{Social Phobia Inventory (SPIN)}

This instrument was formulated to quantify the physiological symptoms of social anxiety-related fear and avoidance. ${ }^{15} \mathrm{~A}$ version translated into and adapted for Brazilian Portuguese was used (Cronbach's alpha = $0.71-0.90$ ) and a cutoff point of 19 was established to define social anxiety. ${ }^{16}$

\section{Trait Questionnaire of the State-Trait Anxiety Inventory (STAI-T)}

This instrument was developed by Spielberger, Gorsuch and Lushene in 1970 and has been translated into and validated for Brazilian Portuguese. ${ }^{17}$ It assesses trait anxiety (how individuals generally feel) through 20 statements, which participants respond to on a fourpoint Likert scale (almost always - almost never). In the present study, the internal consistency of the instrument was $a=0.88$.

\section{Patient Health Questionnaire - 2 (PHQ-2)}

This instrument was designed for screening depressive episodes using two items investigating presence of symptoms over the previous 15 days. Participants respond to the items on a four-point Likert scale. ${ }^{18} \mathrm{~A}$ version translated into and adapted for Brazilian Portuguese was used and the cutoff point adopted to define presence of depression was 3.19 The internal consistency of this instrument in the present study was 0.75 .

\section{Alcohol Use Disorders Identification Test (AUDIT)}

This test was originally developed by the World Health Organization at the end of the 1980s. AUDIT is one of the most widely used measurements in the world for identifying high-risk groups and screening for inappropriate alcohol use. A version translated into Brazilian Portuguese was used. The internal consistency was $a=0.81$, and the cutoff point indicative of alcoholrelated disorders was 8 , as suggested by Lima et al. ${ }^{20}$

\section{Identification Questionnaire}

This questionnaire comprises 12 items on the sociodemographic and musical characteristics of the sample.

The instruments were administered individually. Participants were provided with notebooks containing the instruments described above, accompanied by written instructions. A previously trained examiner was available at the time of administration to provide guidance and clarifications as needed.

Data were analyzed using the Statistical Package for the Social Sciences (SPSS), version 18. Descriptive statistics (mean, standard deviation and percentages) were used to characterize the sample, the musicians' clinical profile, aspects related to perceived causes of MPA and coping strategies. Correlation analysis (Pearson's correlation test) and logistic regression (backward method) were used to evaluate associations among the different clinical variables.

Musical training and clinical status (MPA levels) variables were compared using the chi-square and Student's $t$ tests. The effect size of differences was estimated using Cohen's $d$ and categorized as follows: small, $0.20 \leq d<0.5$; medium, $0.50 \leq d<0.8$; or large, $d \geq 0.80 .^{21}$

The significance level was set at 0.05 in all analyses.

\section{Results}

The sociodemographic, clinical and musical characteristics of the sample are described in Table 1.

With regard to the data described in Table 1 , it is noteworthy that many of the musicians who reported taking medications $(n=39)$ stated that they did so to treat heart, thyroid and gastrointestinal problems. Only $4 \%$ of the participants $(n=9)$ reported taking psychotropic agents and $0.9 \%$ reported taking beta blockers $(n=2)$.

Table 2 lists results for psychiatric indicators as a function of MPA levels. Considering the cutoff points adopted, approximately $37 \%$ of the participants exhibited social anxiety, $40 \%$ exhibited high MPA levels, $12.5 \%$ exhibited depression, and $13.5 \%$ exhibited alcohol abuse. Analysis of the indicators as a function of the MPA levels showed that participants with high levels exhibited a more severe clinical profile (except for alcohol abuse). The effect sizes of these differences were large. Correlations between MPA and these variables were significant and of moderate magnitude (social anxiety: 0.60; anxiety-trait: 0.62; anxiety sensitivity: 0.53 ; depression: 0.40 ). Presence of social anxiety was a predictive factor for MPA (odds ratio = $8.18 ; 95 \% \mathrm{CI}=4.3-15.5)$. It is noteworthy that $70 \%$ of the musicians with indications of social anxiety had high MPA levels and $66 \%$ of the musicians with high MPA levels had indications of social anxiety.

Comparison of the participants as a function of their musical training did not reveal significant differences in 
the psychiatric indicators, with the exception of the social subscale of the anxiety sensitivity index ( $p=0.01)$, on which classical musicians exhibited higher levels of sensitivity to aspects related to social assessment, with a medium effect size ( $d=-0.35$ ) (see supplementary material S1 for more information).
Table 3 lists the participants' assessments of the perceived causes of MPA as a function of MPA level.

The most commonly perceived causes of MPA mentioned by more than half of the sample - were pressure from self, attempting a difficult repertoire, uncertainty attributable to technical flaws, concern

Table 1 - Sociodemographic, clinical and musical characteristics of the sample of Brazilian musicians analyzed $(n=214)$

\begin{tabular}{|c|c|c|c|c|c|}
\hline Variables & $\mathbf{n}$ & $\%$ & Variables & $\mathbf{n}$ & $\%$ \\
\hline \multicolumn{3}{|l|}{ Sex } & \multirow{2}{*}{\multicolumn{3}{|c|}{ Instruments* }} \\
\hline Male & 143 & 67.6 & & & \\
\hline \multirow{2}{*}{ Female } & \multirow{2}{*}{71} & \multirow{2}{*}{32.4} & String & 90 & 42.1 \\
\hline & & & Voice & 29 & 13.5 \\
\hline \multirow[t]{2}{*}{ Age, mean (SD) } & \multirow{2}{*}{\multicolumn{2}{|c|}{$34.0(14.3)$}} & Wind & 31 & 14.4 \\
\hline & & & Percussion & 14 & 6.5 \\
\hline \multicolumn{3}{|l|}{ Marital status } & Piano & 24 & 11.2 \\
\hline Without partner & 142 & 67.6 & Other & 1 & 0.5 \\
\hline With partner & 68 & 32.4 & Several & 21 & 9.9 \\
\hline NR & 4 & & NR & 4 & \\
\hline \multicolumn{3}{|l|}{ Educational level } & \multicolumn{3}{|c|}{ Music performance anxiety } \\
\hline Up to 11 years of formal schooling & 61 & 30.5 & High level & 83 & 39.7 \\
\hline$>11$ years of formal schooling & 139 & 69.5 & Low level & 126 & 60.3 \\
\hline \multirow[t]{2}{*}{ NR } & \multicolumn{2}{|l|}{14} & NR & 5 & \\
\hline \multirow{2}{*}{\multicolumn{3}{|c|}{ Musical training }} & \multicolumn{3}{|c|}{ Use of medication } \\
\hline & & 53.3 & Yes & 39 & 18.9 \\
\hline $\begin{array}{l}\text { Classical musiclans } \\
\text { Popular musicians }\end{array}$ & $\begin{array}{l}114 \\
100\end{array}$ & 46.7 & No & 167 & 81.1 \\
\hline & 100 & 46.1 & NR & 8 & \\
\hline
\end{tabular}

Table 2 - Psychiatric indicators in the sample analyzed, as a function of levels of music performance anxiety

\begin{tabular}{|c|c|c|c|c|}
\hline Psychiatric indicators* & $\begin{array}{c}\text { High MPA levels } \\
(n=83)\end{array}$ & $\begin{array}{c}\text { Low MPA levels } \\
(n=126)\end{array}$ & $\mathbf{p}$ & $\begin{array}{l}\text { Effect size } \\
\text { Cohen's d }\end{array}$ \\
\hline Anxiety - STAI-T, mean (SD) & $49.5(11.4)$ & $35.9(7.8)$ & $<0.001^{\ddagger}$ & -1.45 \\
\hline Social anxiety - SPIN, mean (SD) & $24.7(13.1)$ & $11.3(9.1)$ & $<0.001^{\ddagger}$ & -1.23 \\
\hline Yes $(\%)^{+}$ & 65.1 & 18.3 & & \\
\hline \multicolumn{5}{|l|}{ Anxiety sensitivity - ASI } \\
\hline ASI_total score, mean (SD) & $22.3(11.9)$ & $13.0(8.4)$ & $<0.001^{\ddagger}$ & -0.94 \\
\hline ASI_physical subscale, mean (SD) & $10.22(7.2)$ & $5.08(5.0)$ & $<0.001^{\ddagger}$ & -0.86 \\
\hline ASI_mental subscale, mean (SD) & $3.79(3.27)$ & $1.92(1.99)$ & $<0.001^{\ddagger}$ & -0.73 \\
\hline ASI_social subscale, mean (SD) & $8.28(3.2)$ & $5.97(3.5)$ & $<0.001^{\ddagger}$ & -0.68 \\
\hline Depression - PHQ2, mean (SD) & $1.8(1.5)$ & $0.7(1.1)$ & $<0.001^{\ddagger}$ & -0.86 \\
\hline Yes $(\%)^{+}$ & 25.3 & 4.0 & & \\
\hline Alcohol abuse - AUDIT, mean (SD) & $4.0(5.8)$ & $3.5(4.5)$ & 0.511 & -0.09 \\
\hline Yes $(\%)^{\dagger}$ & 16.9 & 11.1 & & \\
\hline
\end{tabular}

ASI = Anxiety Sensitivity Index; AUDIT = Alcohol Use Disorders Identification Test; MPA = music performance anxiety; PHQ2 = Patient Health Questionnaire - 2; SD: standard deviation; SPIN = Social Phobia Inventory; STAI-T = Trait questionnaire from the State-Trait Anxiety Inventory.

* Five musicians were excluded from this analysis because they did not respond to the KMPAI correctly, so MPA severity could not be assessed.

+ Percentage of individuals with scores over the cutoff point suggested in the psychometric study cited in the Methods section; $\mathrm{p}$ : significance level

* Statistical significance. 
about audience reaction/evaluation, and presence of trait anxiety. The least frequently perceived causes of MPA were pressure from parents/teachers and a lack of support from close people.

When comparing participants with high and low levels of anxiety, with the exceptions of causes involving inadequate preparation, a lack of support from close people, and pressure from parents/teachers, the group with a high MPA level assessed the situations most frequently associated with anxiety, among which pressure from self and concern about audience reaction/ evaluation stood out. These were also the situations most frequently mentioned as the primary cause of anxiety.

Analysis of the musicians according to their musical training showed that classical musicians mentioned the following as the main causes of MPA: pressure from self, uncertainty attributable to technical flaws, and a difficult repertoire. It should be noted that although pressure from parents and lack of support from close people were not frequently cited by the participants in this group, they were rated as having a high degree of relevance by those participants who did mention them.

Among the popular musicians, there was a trend toward mentioning a broader variety of anxietyinducing situations as cause of MPA, denoting a degree of heterogeneity. Presence of trait anxiety and concern about audience reaction/evaluation were frequently cited and rated at a high degree of relevance. Situations such as lack of support from close people, pressure from parents, inadequate preparation, lack of selfconfidence, health issues, lack of confidence, pressure from teachers and pressure from self were ascribed high values (high degree of relevance), but were seldom mentioned (less frequent) (see supplementary material S2 for more information).

Table 4 lists the coping strategies employed by the musicians analyzed and their degree of effectiveness.

Overall, the coping strategies most frequently employed by the whole sample involved use of the individuals' internal/personal resources. The following strategies stood out in terms of frequency and were

Table 3 - Perceived causes of music performance anxiety, as a function of MPA levels

\begin{tabular}{|c|c|c|c|c|c|}
\hline \multirow[b]{2}{*}{ Perceived causes of anxiety*+ } & \multicolumn{2}{|c|}{$\begin{array}{l}\text { High MPA levels } \\
(n=83)\end{array}$} & \multicolumn{2}{|c|}{$\begin{array}{l}\text { Low MPA levels } \\
(n=126)\end{array}$} & \multirow[b]{2}{*}{$\mathbf{p}$} \\
\hline & Yes & $\mathbf{R 1}$ & Yes & $\mathbf{R 1}$ & \\
\hline Health problems when playing & 33 & 1.2 & 25 & 4.0 & $0.001^{\ddagger}$ \\
\hline Difficult repertoire & 61 & 1.2 & 71 & 12.7 & $0.010^{\ddagger}$ \\
\hline Bad performance experience & 58 & 1.2 & 43 & 0 & $<0.001^{\ddagger}$ \\
\hline Concern about audience reaction/evaluation & 70 & 14.5 & 46 & 4.3 & $0.001^{\ddagger}$ \\
\hline Concern about reliability of memory & 48 & 6.0 & 49 & 6.4 & $0.007^{\ddagger}$ \\
\hline Presence of physical symptoms & 57 & 7.2 & 41 & 4.0 & $<0.001^{\ddagger}$ \\
\hline Lack of self-confidence & 47 & 2.4 & 16 & 0 & $<0.001^{\ddagger}$ \\
\hline High level of self-consciousness & 37 & 1.2 & 40 & 4.8 & $0.023^{\ddagger}$ \\
\hline Low self-esteem & 47 & 2.4 & 17 & 1.6 & $<0.001^{\ddagger}$ \\
\hline Inadequate preparation & 43 & 4.8 & 52 & 10.3 & 0.101 \\
\hline Lack of support from close people & 12 & 1.2 & 20 & 0.8 & 0.930 \\
\hline Lack of confidence & 58 & 3.6 & 24 & 2.4 & $<0.001^{\ddagger}$ \\
\hline Negative thoughts/worried about performing & 60 & 3.6 & 39 & 1.6 & $<0.001^{\ddagger}$ \\
\hline Negative performance feedback & 50 & 1.2 & 36 & 1.6 & $<0.001^{\ddagger}$ \\
\hline Difficulty in coping with performance-related negative thoughts & 44 & 2.4 & 18 & 0 & $<0.001^{\ddagger}$ \\
\hline Difficulty in coping with performance-related physical symptoms & 39 & 7.2 & 26 & 2.4 & $<0.001^{\ddagger}$ \\
\hline Pressure from parents & 4 & 0 & 5 & 1.6 & 0.72 \\
\hline Pressure from teachers & 15 & 1.2 & 18 & 0 & 0.39 \\
\hline Pressure from self & 71 & 13.3 & 76 & 13.5 & $<0.001^{\ddagger}$ \\
\hline Pressure from competition & 39 & 1.2 & 25 & 0 & $<0.001^{\ddagger}$ \\
\hline Technical flaws that cause uncertainty & 59 & 4.8 & 59 & 1.6 & $<0.001^{\ddagger}$ \\
\hline Trait anxiety & 69 & 12.0 & 45 & 7.9 & $<0.001^{\ddagger}$ \\
\hline
\end{tabular}

MPA = music performance anxiety; R1 = percentage relative to the cause classified as most relevant - score 1.

* Five musicians were excluded from this analysis because they did not respond to the KMPAI correctly, so MPA severity could not be assessed.

+ Nonexclusive categories.

* Statistical significance. 
also were deemed relatively effective: deep breathing, increasing practice, familiarizing oneself with the venue, and relaxation techniques. The most effective techniques ( $\geq 65 \%$ rated them as effective) involved use of medications and seeking psychiatric help. However, these techniques were employed the least often.

Musicians with high and low MPA levels used similar coping strategies. Significant differences were only observed for frequency of use of anxiolytics and beta blockers, discussing anxiety with family/friends, and consulting a psychologist, which were more frequently employed by musicians with high MPA levels.

Although there was no difference between classical and popular musicians in terms of the strategies they used most and least frequently, the former more frequently used beta blockers and relaxation techniques, more frequently discussed their anxiety, with their music teachers, and more frequently sought to familiarize themselves with the performance venue.

The effectiveness of coping strategies was similar between the groups with and without high MPA. It is noteworthy that breathing and familiarizing oneself with the performance venue were more effective among the participants with low MPA levels. Use of distraction methods and deep breathing were less effective among the classical musicians (see supplementary material S3 to $\mathbf{S} 6$ for more information).

\section{Discussion}

This study investigated the clinical profile, perceived causes and coping strategies of MPA among a sample of Brazilian musicians. High percentages of pathological indicators were detected in comparison with the overall Brazilian population, ${ }^{22}$ even taking into account the false-negative rates of the screening instruments used. In a population-based study conducted by Andrade et al., ${ }^{22}$ rates of social anxiety, depression, and alcohol abuse were $3.5 \%, 9.4 \%$, and $2.7 \%$, respectively, whereas the rates identified in the present study were $37.0 \%, 12.5 \%$, and $13.5 \%$, respectively. These data are alarming and provide evidence of the extreme vulnerability of this population group.

Approximately $40 \%$ of the participants exhibited pathological levels of MPA. Although this rate is higher than was detected in a previous study ${ }^{2}$ it is consistent with the higher rates reported in studies performed with samples of Dutch and Japanese musicians (59\% and 64\%). ${ }^{23,24}$ As expected, musicians with high MPA levels also more frequently displayed the other pathological indicators analyzed; a finding that reinforces the association between MPA and psychiatric comorbidities. ${ }^{2,3}$ These findings also add weight to the results of previous studies suggesting that MPA is a subtype of social anxiety ${ }^{3,25,26}$ that can be predicted by

Table 4 - Coping strategies used by musicians to deal with MPA situations, classified according to frequency of use and level of effectiveness

\begin{tabular}{|c|c|c|c|c|c|c|}
\hline \multirow[b]{2}{*}{ Coping strategies* } & \multicolumn{2}{|c|}{$\begin{array}{c}\text { Musicians who use } \\
\text { strategy }\end{array}$} & \multicolumn{2}{|c|}{$\begin{array}{c}\text { Frequency of use } \\
(\%)\end{array}$} & \multicolumn{2}{|c|}{$\begin{array}{c}\text { Effectiveness } \\
(\%)\end{array}$} \\
\hline & $\mathbf{n}$ & $\%$ & 1st & 2nd & $\mathbf{0}$ & 1 \\
\hline Alcohol & 22 & 10.3 & 40.9 & 13.6 & 40.9 & 59.1 \\
\hline Antidepressants & 2 & 0.9 & 50.0 & -- & 50.0 & 50.0 \\
\hline Anxiety medications & 17 & 7.9 & 41.2 & 11.8 & 35.3 & 64.7 \\
\hline Beta blockers & 21 & 9.8 & 52.4 & -- & 19.0 & 81.0 \\
\hline Deep breathing & 142 & 66.3 & 46.5 & 21.8 & 29.2 & 70.8 \\
\hline Distraction methods & 37 & 17.3 & 16.2 & 32.4 & 42.5 & 57.5 \\
\hline Discuss anxiety with family/friends & 57 & 26.6 & 12.3 & 19.3 & 58.2 & 41.8 \\
\hline Discuss anxiety with music teacher & 41 & 19.2 & 7.3 & 17.1 & 46.3 & 53.7 \\
\hline Consult doctor & 7 & 3.3 & 14.3 & 14.3 & 60.0 & 40.0 \\
\hline Consult psychologist & 17 & 7.9 & 14.3 & 23.5 & 53.3 & 46.7 \\
\hline Consult psychiatrist & 9 & 4.2 & 22.2 & 11.1 & 28.6 & 71.4 \\
\hline Familiarize self with venue & 98 & 45.8 & 23.5 & 13.3 & 68.1 & 31.9 \\
\hline Hypnosis & 5 & 2.3 & 20.0 & 40.0 & 66.7 & 33.3 \\
\hline Increase practice & 114 & 53.3 & 27.2 & 31.6 & 51.1 & 48.9 \\
\hline Mock performance practice & 64 & 29.9 & 12.5 & 17.2 & 35.5 & 64.5 \\
\hline Use nonprescribed medication & 6 & 2.8 & 50.0 & 33.3 & 50.0 & 50.0 \\
\hline Positive self-talk & 58 & 27.1 & 15.5 & 12.1 & 56.1 & 43.9 \\
\hline Relaxation techniques & 93 & 43.5 & 12.9 & 31.2 & 30.4 & 69.6 \\
\hline
\end{tabular}

$\%=$ percentage relative to the number of participants who reported using the particular strategy; 1 st $=$ first most frequently employed strategy, 2 nd $=$ second most frequently employed strategy; $0=$ not effective/relatively ineffective; 1 = quite/very effective.

* Nonexclusive categories. 
this disorder and shares the same theoretical cognitivebehavioral model. 27,28

However, contrary to expectations, classical musicians (considered to be high performance musicians) did not exhibit higher levels of MPA or other psychopathologies, which contradicts the hypothesis that high demands and long hours of preparation before a performance both so common in the lives of orchestra musicians are risk factors for mental health problems among this population.

However, the classical musicians did exhibit higher rates of anxiety sensitivity with relation to social exposure. Fear of the uncomfortable feelings of anxiety that characterize anxiety sensitivity and a belief that such feelings might have negative social consequences, in addition to the high levels of demands imposed by the musicians themselves and the audience, might be related to this finding. ${ }^{29}$ Considering that the musicians' condition/profession necessarily involves heavy social exposure, which is intrinsic to musical practice, experiences of suffering and/or loss are a part of everyday life in the music world.

Regardless of their professional and clinical characteristics, all the musicians analyzed cited the following as the most frequently perceived causes of MPA: pressure from self, attempting a difficult repertoire, uncertainties attributable to technical flaws, and concern about audience reaction/evaluation. This finding corroborates the theoretical model developed by Valentine, ${ }^{30}$ which emphasizes participation of variables related to the individual, the task, and the situation in the etiology of MPA. Individual-related causes predominated among the causes most frequently cited by the classical musicians and/or the musicians with high levels of MPA (pressure from self, uncertainty attributable to technical flaws, and concern about audience reaction), which might be related to self-esteem issues and perfectionism, which in turn may be more common among musicians with these characteristics.

Kemp ${ }^{31}$ and Lehmann et al. ${ }^{32}$ have emphasized the relevance of cognitive processes. According to these authors, ways of thinking and interpreting aspects of musical performance are impregnated by negative beliefs about oneself and one's own performance that have developed throughout life and may result in the perception of performance as threatening. This situation might further contribute to facilitating experiences of anxiety, low self-esteem, and high levels of perfectionistic concerns (excessive worry, negative reaction and doubts relative to one's own actions, in addition to a rigid view of success and failure). ${ }^{14}$

Concern about audience reaction/evaluation is a core aspect of MPA and is related to both the individual and the situation. Therefore, it was unsurprising that this concern was the most frequently cited cause of MPA by participants with higher levels of symptoms, who might interpret the audience's judgment as threatening and negative. ${ }^{32}$ This negative and intimidating interpretation of social judgment is a core aspect of social anxiety disorder. ${ }^{1}$

Uncertainty caused by technical flaws (which is both an individual and a task-related cause) was more frequently cited by the classical musicians than the popular musicians. This finding might be related to greater sensitivity to one's own flaws and the demands inherently imposed on high-performance musicians. Within this context, technique plays a significant role vis-à-vis performance, favoring an increase in anxiety experienced as a function not only of the audience evaluation but also of the technical-interpretive assessment of critics, teachers, conductors and orchestras.

With respect to task-related causes, regardless of their training and level of MPA, the musicians analyzed emphasized attempting difficult repertoires. According to Sinico \& Winter, ${ }^{33}$ the repertoire played should take into account the demands inherent to the task and the musician's skills to avoid a possible mismatch between these two factors that increases the likelihood of occurrence of symptoms of anxiety. However, these authors also considered that dysfunctional beliefs relative to both repertoire difficulty and the musician's musical skills might contribute to increased anxiety. This hypothesis is consistent with the specialized literature that emphasizes the relevance of cognitive symptoms (distorted thoughts and beliefs) in the genesis and maintenance of anxiety and MPA. ${ }^{5,32}$

Classical musicians and/or musicians with high levels of MPA cited a broader variety and higher frequency of causes of MPA. This fact may be related to the higher levels of anxiety sensitivity exhibited by these two groups compared with all others. Another possible explanation is that the classical musicians mentioned a larger number of causes as a function of the pressure and high demands typical of the profession, as previously reported in the literature. ${ }^{34,35}$

The poorer clinical profile of the participants with high MPA levels may have favored their identification of and their sensitization to a larger number of causes of MPA.

Considering the wide variety of situations that make occurrence of MPA symptoms more likely, it is crucial to acquire accurate knowledge of both the resources musicians deploy to cope with and minimize the symptoms and the level of those resources' effectiveness, approached from the perspective known 
in the literature as coping strategies. Coping strategies are behavioral and cognitive practices that can be learned and are used to address internal or external stimuli that are interpreted as intimidating or threatening. ${ }^{36}$ Kenny ${ }^{14}$ adapted this notion to the musical setting and defined it as the set of cognitive-behavioral skills employed for coping with MPA symptoms.

Lazarus \& Folkman ${ }^{37}$ divided coping strategies into two distinct categories: a) problem-focused coping, which encompasses varying behaviors that seek to solve problems associated with an aversive stimulus, and b) emotion-focused coping, which is characterized by strategies that seek to develop new ways to interpret and experience aversive stimuli. According to these authors, the choice of a given strategy depends on the situation individuals face and their repertoire of skills and internal resources.

The coping strategies most often employed by the musicians analyzed in the present study were deep breathing, increased practice, familiarizing themselves with the performance venue and relaxation techniques. These preferences were common to the various groups of musicians and are consistent with previous reports in the literature, ${ }^{38,39}$ thus reinforcing the predominance of emotion-focused strategies. Although the effectiveness of these strategies was rated as reasonable by the participants, the strategies were less effective for both the participants with high levels of MPA and the classical musicians.

In contrast, problem-focused strategies, which also include seeking healthcare professionals and services (i.e., external resources), were used less often, even though they were perceived to be more effective. The low frequency of seeking medical and psychological care is noteworthy and might reinforce a previous statement in the literature, ${ }^{2,14}$ that musicians see MPA as a normal and typical aspect of their profession. This attitude hinders musicians from seeking specialized help, thereby rendering it even more difficult for healthcare professionals to screen for and detect this problem.

The aforementioned considerations evidence the relevance of campaigns to raise awareness of this condition, to explain it, and to publicize the availability of specialized services for the affected population. Although infrequent, MPA is associated with increased procurement of psychological care. That psychologists are rarely consulted is regrettable, since their therapeutic resources include cognitive-behavioral therapy, which is one of the intervention modalities for treating MPA for which there is the greatest evidence of effectiveness, according to a literature review. ${ }^{40}$

The frequency of use of beta blockers was similar to the frequency reported in another Brazilian study that assessed students studying for music degrees $(17.3 \%),{ }^{8}$ but lower than the frequency found in a study conducted with orchestra musicians in Australia (30.9\%). ${ }^{41}$ This strategy was rated as effective by $80 \%$ of the classical musicians and $73.3 \%$ of the musicians with high MPA levels who reported using it. The musicians who benefited from beta blockers were possibly those most affected by the physiological symptoms of anxiety because these drugs have no effect on cognitive, emotional, or psychological symptoms. ${ }^{14}$ These findings reinforce reports in the literature ${ }^{6,7,42}$ on the frequent use of this medication by musicians, especially highperformance musicians, ${ }^{43}$ primarily to obtain relief from symptoms such as palpitations, hyperventilation, tremors and nausea. ${ }^{44}$

Use of anxiolytics was reported with low frequency, but was rated highly effective. This low frequency of use may be attributable to the undesirable side effects of these drugs, such as impairment of fine motor coordination and performance quality. ${ }^{8}$

Although also of low frequency, seeking support from family, friends and teachers was more frequent among both classical musicians and musicians with high MPA levels. It is worth stressing the relevant role of music teachers in the training and guidance of their students, which might be a key element in the process of identifying, understanding and managing MPA. However, as Nascimento ${ }^{8}$ observed, more than half of teachers do not provide their students with information about coping strategies, and when they do, their advice is based on common sense rather than on the information available in the literature. Ray et al. ${ }^{45}$ analyzed the curricula of various higher education music schools across Brazil and observed that psychological education was scarce in the field of musical training and that little information was provided about psychology as it relates to music performance.

Regardless of their professional training, support from family and friends was highly relevant to the participants in this study. The family and social environments may be perceived as imposing less pressure and fewer demands than the music environment and are more sensitive to suffering. These findings are consistent with Dews \& Williams, ${ }^{46}$ who reported that friends were named as the primary network of support for music students, whereas formal counseling was rated as the last resource.

One further coping strategy for MPA that merits mention is alcohol consumption. Indeed, in this study, $25 \%$ of the participants who reported drinking as a way to cope with MPA exhibited alcohol abuse and rated this strategy as highly effective. This behavior also occurs among individuals with social anxiety, who often drink 
as a way to cope with anxiety when in situations of exposure. ${ }^{47}$ We call attention to the risks associated with alcohol consumption.

Although the strategies most frequently used were ascribed some degree of effectiveness, it is curious that the most effective strategies were not the most frequently used and that some of the least frequently used strategies were rated highly effective. This incongruence calls for serious reflection, especially on the possibility of failure in the management of MPA and the intense suffering experienced by musicians.

These findings reinforce Mejía's ${ }^{48}$ observation that musicians employ a wide variety of strategies to cope with MPA intuitively, possibly without guidance from teachers and healthcare providers. To this, one should add the nearly absolute lack of specialized services for the treatment of MPA and other psychopathologies among musicians, particularly in Brazil, and also of initiatives within education and public policy settings for the prevention and promotion of the physical and mental health of musicians.

The main limitation of the present study was the use of self-report scales on signs and symptoms for evaluating psychopathological conditions, especially MPA. Use of structured interviews or clinical diagnosis is suggested for future studies.

\section{Conclusion}

The results of this study support the conclusion that there was a high prevalence of MPA among Brazilian musicians, regardless of their field of activity and professional training. A wide variety of situations were associated with occurrence of MPA, among which individual-related situations - particularly pressure from self and concern about audience reaction were prominent. Emotion-focused coping and internal resources stood out among the resources for coping with MPA, even when they were not always effective. The respondents seldom reported seeking specialized resources and treatments, which is evidence of the vulnerability of the targeted population group and of the need for action to change this scenario.

\section{Acknowledgements}

This study received financial support from Fundação de Amparo à Pesquisa do Estado de São Paulo (FAPESP; process no. 301321/2016-7) and from Conselho Nacional de Desenvolvimento Científico e Tecnológico (CNPq; process no. 301321/2016-7).

\section{Disclosure}

No conflicts of interest declared concerning the publication of this article.

\section{References}

1. American Psychiatric Association. Diagnostic and Statistical Manual of Mental Disorders, Fifth Edition (DSM-5). Arlington: American Psychiatric Publishing; 2013.

2. Barbar AE, Crippa JA, Osório FL. Performance anxiety in Brazilian musicians: prevalence and association with psychopathology indicators. J Affect Disord. 2014;152:381-6.

3. Osborne MS, Franklin J. Cognitive processes in music performance anxiety. Aust J Psychol. 2008;54:86-9.

4. Burin $A B$, Osório FL. Interventions for music performance anxiety: results from a systematic literature review. Arch Clin Psychiatry. 2016;43:116-31.

5. Steptoe A. Negative emotions in music making: the problem of performance anxiety. In: Juslin PN, Sloboda JA, editors. Music \& emotion: theory and research. New York: Oxford University Press; 2001. p. 291-307.

6. Brugués AO. Music performance anxiety-part 2: a review of treatment options. Med Probl Perform Art. 2011;26:164-71.

7. Kenny D. A systematic review of treatments for music performance anxiety. Anxiety Stress Coping. 2005;18:183-208.

8. Nascimento SEF. Ansiedade de performance musical: um estudo sobre o uso de betabloqueadores por bacharelandos em música [dissertation]. Belo Horizonte: Universidade Federal de Minas Gerais; 2013.

9. Kenny DT. The factor structure of the revised Kenny Music Performance Anxiety Inventory. In: International Symposium on Performance Science; 2009; Auckland, New Zealand.

10. Kenny D, Davis $P$, Oates J. Music performance anxiety and occupational stress amongst opera chorus artists and their relationship with state and trait anxiety and perfectionism. J Anxiety Disord. 2004;18:757-77.

11. Rocha SF, Dias-Neto E, Gattaz WF. Anxiety in musical performance: translation, adaptation and validity of Kenny Music Performance Anxiety Inventory (K-MPAI) for the Portuguese language. Rev Psiquiatr Clin. 2011;38:217-21.

12. Reiss S, Peterson RA, Taylor S, Schimidt NB. Anxiety sensitivity index consolidated user manual: ASI, ASI-3, and CASI. Worthington: IDS Publishing; 2008.

13. Burin AB. Ansiedade de performance musical: causas percebidas, estratégias de enfrentamento e perfil clínico de músicos brasileiros e australianos [dissertation]. Ribeirão Preto: Universidade de São Paulo; 2017.

14. Kenny DT. The psychology of music performance anxiety. Oxford: Oxford University Press; 2011.

15. Connor KM, Davidson JR, Churchill LE, Sherwood A, Foa E, Weisler $\mathrm{RH}$. Psychometric properties of the Social Phobia Inventory (SPIN): a new self-rating scale. Br J Psychiatry. 2000;176:37986.

16. Osório FL, Crippa JAS, Loureiro SR. Social Phobia Inventory (SPIN): validation for Brazil. Rev Psiquiatr Clin. 2004;26:25-9.

17. Biaggio AMB, Natalício $L$, Spielberger CD. Development of the Portuguese experimental form of the Spielberger Trait-State Anxiety Inventory (IDATE). Arq Bras Psicol. 1977;29:31-44.

18. Kroenke K, Spitzer RL, Williams JBW. The PHQ-9: validity of a brief depression severity measure. J Gen Intern Med. 2001;16:60613.

19. Osório FL, Vilela Mendes A, Crippa JAS, Loureiro SR. Study of the discriminative validity of the PHQ-9 and PHQ-2 in a sample of Brazilian women in the context of primary health care. Perspect Psychiatr Care. 2009;45:216-27.

20. Lima CT, Freire AC, Silva AP, Teixeira RM, Farrel M, Prince M. Concurrent and construct validity of the AUDIT in an urban Brazilian sample. Alcohol Alcohol. 2005;40:584-9.

21. Cohen J. Statistical power analysis for the behavioral sciences. 2nd ed. Hillsdale: Lawrence Earlbaum; 1988.

22. Andrade LH, Wang YP, Andreoni S, Silveira CS, Alexandrino-Silva C, Siu ER, et al. Mental disorders in megacities: findings from 
the Sao Paulo Megacity Mental Health Survey, Brazil. PLoS One. 2012;7:1-11.

23. Van Kemenade JFLM, Van Son MJM, Van Heesch NC. Performance anxiety among professional musicians in symphonic orchestras: a self-report study. Psychol Rep. 1995;77:555-62.

24. Yoshie M, Kudo K, Ohtsuki T. Effects of psychological stress on state anxiety, electromyographic activity, and arpeggio performance in pianists. Med Probl Perform Art. 2008;23:120-32.

25. Barlow DH. Anxiety and its disorders. New York: Guilford Press; 1988.

26. Clark DB, Agras WS. The assessment and treatment of performance anxiety in musicians. Am J Psychiatry. 1991;148:598-605.

27. Rapee RM, Heimberg RG. A cognitive-behavioral model of anxiety in social phobia. Behav Res Ther. 1997;35:741-56.

28. Sabino ADV, Camargo CM, Chagas MHN, Osório FL. Facial recognition of happiness is impaired in musicians with high music performance anxiety. Front Psychiatry. 2018;9:5.

29. Reiss S, McNally RJ. The expectancy model of fear. In Reiss S, Bootzin RR, editors. Theoretical issues in behavior therapy. New York: Academic Press; 1985. p. 107-21.

30. Valentine E. The fear of performance. In: Rink J, editor. Musical performance: a guide to understanding. Cambridge: Cambridge University Press; 2002. p. 168-82.

31. Kemp AE. The musical temperament: psychology and personality of musicians. New York: Oxford University Press; 1996.

32. Lehmann A, Sloboda J, Woody R. Psychology for musicians: understanding and acquiring the skills. New York: Oxford Press; 2007.

33. Sinico A, Winter L. A influência do repertório sob a ansiedade na performance musical de estudantes de flauta. In: XXIII Congresso da Associação Nacional de Pesquisa e Pós-Graduação em Música; 2013; Natal, RN, Brazil. [cited 2017 Aug 08]. http://www. anppom.com.br/congressos/index.php/23anppom/Natal2013/ paper/viewFile/2073/528

34. Kenny D, Ackermann B. Performance-related musculoskeletal pain, depression and music performance anxiety in professional orchestral musicians: a population study. Psychol Music. 2013;43:1-18.

35. Persson RS. The maestro music teacher and musicians' mental health. In: 104th Annual Convention of the American Psychological Association in Toronto; 1996; Toronto, Canada.

36. Antoniazzi AS, Dell'Aglio DD, Bandeira DR. The concept of coping: a theoretical revision. Estud Psicol. 1988;3:273-94.

37. Lazarus RS, Folkman S. Stress, appraisal, and coping. New York: Springer; 1884.
38. Studer R, Gomez P, Hildebrandt H, Arial M, Danuser B. Stage fright: its experience as a problem and coping with it. Int Arch Occup Environ Health. 2011;84:761-71.

39. Zakaria JB, Musib HB, Shariff SM. Overcoming performance anxiety among music undergraduates. Procedia Soc Behav Sci. 2013;90:226-34.

40. Burin $A B$, Osório FL. Interventions for music performance anxiety: results from a systematic literature review. Arch Clin Psychiatry. 2016;43:116-31.

41. Kenny D, Driscoll T, Ackermann B. Psychological well-being in professional orchestral musicians in Australia: a descriptive population study. Psychol Music. 2014;2:210-32.

42. Fishbein M, Middlestadt SE, Otatti V, Straus S, Ellis A. Medical problems among musicians: overview of a national survey. Med Probl Perform Art. 1988;3:1-8.

43. Maciente MN. Estratégias de enfrentamento para a ansiedade de performance musical (APM): um olhar sobre músicos profissionais de orquestras paulistas [dissertation]. São Paulo: Universidade de São Paulo; 2016.

44. McGrath CE. Music performance anxiety therapies: a review of the literature [dissertation]. Urbana: University of Illinois; 2012.

45. Ray S, Kaminski LC, Dueti R, Fonseca CA, Rocha S, Santos PJP, et al. Exploratory study on the impact of information on performance psychology on the level of stress and anxiety of Brazilian practicing musicians. Opus. 2016;22:303-23.

46. Dews CLB, Williams MS. Student musicians' personality styles, stresses, and coping patterns. Psychol Music. 1989;17:37-47.

47. Bittencourt SA, Oliveira MS, Souza CC. Study of the relationship between social phobia and alcohol use. Rev Bras Ter Cogn. 2005; 1:135-46.

48. Mejía CMG. Estratégias para o controle da ansiedade na performance musical [dissertation]. João Pessoa: Universidade Federal da Paraíba; 2016.

\section{Correspondence:}

Flávia de Lima Osório

Faculdade de Medicina de Ribeirão Preto da Universidade de São Paulo (FMRP-USP)

Avenida dos Bandeirantes, 3900

14048-900 - Ribeirão Preto, SP - Brazil

Tel. : +55 (16) 36022530

E-mail: flaliosorio@gmail.com 